\title{
Rapid systemic surge of IL-33 after severe human trauma: a prospective observational study
}

\author{
Olav Sundnes ${ }^{1,2,3 \dagger} \mathbb{0}$, William Ottestad ${ }^{4,5 \dagger}$, Camilla Schjalm²,6, Peter Lundbäck ${ }^{1,2}$, Lars la Cour Poulsen ${ }^{1,2}$, \\ Tom Eirik Mollnes ${ }^{1,6,7,8}$, Guttorm Haraldsen ${ }^{1,2^{*}+}$ and Torsten Eken ${ }^{4,5+}$
}

\begin{abstract}
Background: Alarmins are considered proximal mediators of the immune response after tissue injury. Understanding their biology could pave the way for development of new therapeutic targets and biomarkers in human disease, including multiple trauma. In this study we explored high-resolution concentration kinetics of the alarmin interleukin-33 (IL-33) early after human trauma.

Methods: Plasma samples were serially collected from 136 trauma patients immediately after hospital admission, 2, 4,6 , and $8 \mathrm{~h}$ thereafter, and every morning in the ICU. Levels of IL-33 and its decoy receptor SST2 were measured by immunoassays.

Results: We observed a rapid and transient surge of IL-33 in a subset of critically injured patients. These patients had more widespread tissue injuries and a greater degree of early coagulopathy. IL-33 half-life $\left(\mathrm{t}_{1 / 2}\right)$ was $1.4 \mathrm{~h}(95 \% \mathrm{Cl}$ 1.2-1.6). SST2 displayed a distinctly different pattern with low initial levels but massive increase at later time points.

Conclusions: We describe for the first time early high-resolution IL-33 concentration kinetics in individual patients after trauma and correlate systemic IL-33 release to clinical data. These findings provide insight into a potentially important axis of danger signaling in humans.
\end{abstract}

Keywords: Alarmins, Interleukin-33, Biomarkers, Immunity, Innate, Wounds and Injuries, Kinetics, Humans, Critical Care, Prospective Studies

\section{Background}

It is well established that the immune system not only discriminates between self and non-self but also responds to insults that affect tissue homeostasis. This concept has been clearly demonstrated in experimental models of sterile tissue damage, shock and reperfusion (Bianchi

\footnotetext{
${ }^{*}$ Correspondence: guttorm.haraldsen@medisin.uio.no

${ }^{\dagger}$ Olav Sundnes and William Ottestad equal contribution by these authors

${ }^{\dagger}$ Guttorm Haraldsen and Torsten Eken equal contribution by these authors

${ }^{1}$ K.G Jebsen Inflammation Research Centre, Institute of Clinical Medicine, Faculty of Medicine, University of Oslo, Oslo, Norway

Full list of author information is available at the end of the article
}

2007; Levy et al. 2007; Matzinger 2002). In patients with severe trauma and shock the innate immune response can lead to unbridled systemic inflammation with subsequent multiple-organ failure (MOF) and adverse outcomes (Stoecklein et al. 2012). The immune response after such tissue damage is thought to be initiated by alarmins, a diverse group of constitutively expressed molecules that are released upon cellular damage (Hirsiger et al. 2012; Hwang et al. 2011). As they are likely the most proximal mediators of the immune response to injury, there is great interest in understanding their biology and their potential as future biomarkers or therapeutic original author(s) and the source, provide a link to the Creative Commons licence, and indicate if changes were made. The images or other third party material in this article are included in the article's Creative Commons licence, unless indicated otherwise in a credit line to the material. If material is not included in the article's Creative Commons licence and your intended use is not permitted by statutory regulation or exceeds the permitted use, you will need to obtain permission directly from the copyright holder. To view a copy of this licence, visit http://creativecommons.org/licenses/by/4.0/. 
targets in a variety of conditions, including the inflammatory sequelae following major trauma.

Interleukin-33 (IL-33) is a novel IL-1 family member known to have pleiotropic effects in both innate and adaptive immunity (Martin and Martin 2016; Molofsky et al. 2015). IL-33 possibly exerts dual functions: one as a nuclear factor and another as an extracellular cytokine signaling through its receptor ST2 (Carriere et al. 2007; Haraldsen et al. 2009). It thus resembles other dualfunction alarmins such as HMGB1 and IL- $1 \alpha$ (Haraldsen et al. 2009). Extensive research to understand IL-33 biology has largely been performed in murine models but its regulation and release to the extracellular environment in human physiology and pathophysiology remains unclear (Martin and Martin 2016). While cellular necrosis appears to be the main mechanism of release, active secretion has also been described (Kakkar et al. 2012; Kouzaki et al. 2011).

We have recently published data on the early concentration kinetics of the prototype alarmin HMGB1 in human trauma patients (Ottestad et al. 2019). Unlike HMGB1, which is nearly ubiquitously expressed (Müller et al. 2004), human IL-33 is restricted to constitutive expression in endothelial cells along the vascular tree, epithelial cells at certain barrier surfaces, and varying constitutive expression in other stromal cell types (Küchler et al. 2008; Pichery et al. 2012). Whether the strong constitutive vascular expression pattern reflects an intracellular function in quiescent endothelial cells is not yet clear, but this location nevertheless indicates that IL-33 is ideally positioned for rapid systemic release upon endothelial injury. Current knowledge of IL-33 biology is largely derived from experimental models in mice. The translational value is limited since mice have a markedly different expression pattern compared to humans (Pichery et al. 2012; Sundnes et al. 2015) and importantly, in the context of tissue injury, lack widespread constitutive expression of IL-33 in the vasculature (Pichery et al. 2012).

The biological activity of IL-33 is tightly regulated and, as described for other IL-1 family members (Granowitz et al. 1991), one level of activity control is the synthesis of a soluble decoy receptor (sST2) (Pascual-Figal and Januzzi 2015). sST2 is abundantly expressed in blood in healthy individuals, with increased levels detected in a variety of conditions. Previous studies have shown that levels of circulating sST2 are markedly increased in trauma patients (Brunner et al. 2004; Du et al. 2018; $\mathrm{Xu}$ et al. 2017). IL-33, on the other hand, appears to be present in very low or undetectable levels in plasma or serum. A few recent studies have assessed IL-33 levels in trauma patients. Xu et al. (2017) analysed plasma sampled upon admission to the trauma ICU and at two additional time points in the first $24 \mathrm{~h}$, followed by daily samples obtained until day 7 or upon discharge from the ICU. They reported that IL-33 levels were increased at admission, were highest in the first four hours after admission, and that levels were elevated for several days. Halát et al. (Halát et al. 2019) also reported elevated plasma levels of IL-33 in samples taken at admission. However, detailed early kinetic data on human IL-33 release has not yet been reported.

In order to study the dynamics of IL-33 release we have analyzed a unique collection of human plasma samples obtained serially with $2 \mathrm{~h}$ time resolution after a broad range of traumatic injuries. We show that IL-33 is released rapidly at detectable levels upon widespread tissue injury, in agreement with its putative role as a damage-released mediator in humans. Furthermore, we report a later increase of its decoy receptor sST2 consistent with a subsequent regulatory response.

\section{Methods}

Trauma patients admitted to Oslo University Hospital Ullevål, a Level 1 trauma center, were included prospectively from January 2011 to January 2014. The cohort was characterized in a recent publication (Ottestad et al. 2019). Patients less than 18 years old, burn injuries, and pregnant women were excluded. Reference values were obtained from 20 healthy volunteers. The Regional committee for medical and health research ethics approved the protocol (2010/2014 REK Sør-Øst D).

Blood was drawn in EDTA-coated tubes immediately after admission to the emergency department, 2, 4, 6, and $8 \mathrm{~h}$ thereafter, and daily in the intensive care unit (ICU) for up to ten days. Arterial samples were preferred in order to obtain blood that was not draining from any particular injured body part. All sampling times were converted to hours post injury. The EDTA tubes were put directly in ice slush and within 15 min centrifuged at $2500 \mathrm{~g}$ for $15 \mathrm{~min}$ at $4{ }^{\circ} \mathrm{C}$. Aliquots of the supernatant were immediately transferred to long-term storage in $1.8 \mathrm{~mL}$ sterile polypropylene tubes (NUNC CryoTubes; Catalog No. 479-6843; VWR International AS, Oslo, Norway) at $-80{ }^{\circ} \mathrm{C}$. Blood sampling and processing was handled by seven individuals dedicated to this project only.

Plasma IL-33 was measured with Bio-Plex Pro Human Th17 Cytokine IL-33 immunoassay (Bio-Rad Laboratories, Hercules, CA). sST2 was analyzed by ELISA in duplicates with Human ST2/IL-1R4 Quantikine kit (R\&D Biosystems, Minneapolis, MN).

Statistical analyses were performed using GraphPad Prism version 6.0 (GraphPad Software, La Jolla, CA) and JMP 11.2.1 (SAS Institute Inc, Cary, NC). Data from NISS > 24 patients stratified according to detectable IL-33 
(IL-33pos) or undetectable (IL-33neg) were compared by the Kruskal-Wallis test with Dunn's multiple comparison test or by $\chi^{2} /$ Fisher's exact test as appropriate. Two-sided $p$-values $<0.05$ were considered statistically significant.

Further details are given in Additional file 1: Methods.

\section{Results and discussion}

A total of 145 trauma patients were enrolled. Two patients withdrew from the study, three were excluded due to enrolment in an interventional study, one was excluded due to age less than 18 years, and three were taken out of the analysis due to unknown time of injury (Ottestad et al. 2019). Characteristics of the 136 patients constituting the study population are given in Table 1 . The majority of patients were male (74\%), median age was 40 years (quartiles 27-54, range 18-94), and blunt trauma was the predominant mechanism of injury (87\%). Total 30-day mortality rate was $15 \%$. The initial blood samples were drawn at a median time of $0: 10 \mathrm{~h}$ (quartiles 0:06-0:16) after arrival in the emergency room, corresponding to a median time of $1: 15 \mathrm{~h}(0: 47-1: 50)$ after injury. The total number of samples analyzed for IL-33 was 1094, and the

Table 1 Clinical characteristics of trauma patients stratified according to trauma severity and detectable IL-33

\begin{tabular}{|c|c|c|c|c|c|c|}
\hline & & \multirow[t]{2}{*}{ NISS $<9$} & \multirow[t]{2}{*}{ NISS 9-24 } & \multicolumn{2}{|l|}{ NISS $>24$} & \multirow{3}{*}{$\begin{array}{l}p \text {-value* } \\
\text { IL-33neg vs pos }\end{array}$} \\
\hline & \multirow[b]{2}{*}{$n$} & & & \multirow{2}{*}{$\begin{array}{l}\text { IL-33neg } \\
- \\
51\end{array}$} & \multirow{2}{*}{$\begin{array}{l}\text { IL-33pos } \\
24\end{array}$} & \\
\hline & & 17 & 44 & & & \\
\hline Age & Years & $35(26-46)$ & $36(28-49)$ & $44(29-62)$ & $39.5(22-61)$ & 0.2609 \\
\hline Male gender & n (\%) & $12(71)$ & $34(77)$ & $38(75)$ & $17(71)$ & 0.6024 \\
\hline Time after injury of first sample & Hours & $0.9(0.8-1.2)$ & $1.1(0.6-1.4)$ & $1.7(1.1-2.5)$ & $1.2(0.8-1.6)$ & 0.0119 \\
\hline Penetrating trauma & n (\%) & $2(12)$ & $8(18)$ & $8(16)$ & $0(0)$ & 0.049 \\
\hline Major head trauma ${ }^{\dagger}$ & n (\%) & $0(0)$ & $7(16)$ & $36(71)$ & $16(67)$ & 0.7913 \\
\hline Isolated major head trauma ${ }^{\ddagger}$ & n (\%) & $0(0)$ & $5(11)$ & $12(24)$ & $0(0)$ & 0.0072 \\
\hline NISS & Score & $2(1-5)$ & $14(10-19)$ & $41(34-57)$ & $49(41-59)$ & 0.3390 \\
\hline ISS & Score & $2(1-5)$ & $10(9-14)$ & $29(21-38)$ & $42(29-50)$ & 0.0278 \\
\hline Number of ISS regions affected & Number & $1(1-2)$ & $2(2-3)$ & $3(2-4)$ & $5(4-5)$ & 0.0001 \\
\hline \multicolumn{7}{|l|}{ Injury to ISS region: } \\
\hline Head or neck & n (\%) & $7(41)$ & $12(27)$ & $36(71)$ & $18(75)$ & 0.7873 \\
\hline Face & n (\%) & $1(6)$ & $10(23)$ & $22(43)$ & $6(25)$ & 0.2004 \\
\hline Chest & n (\%) & $0(0)$ & $19(42)$ & $28(55)$ & $21(88)$ & 0.0084 \\
\hline Abdominal or pelvic contents & n (\%) & $0(0)$ & $7(15)$ & $10(20)$ & $21(88)$ & $<0.0001$ \\
\hline Extremities or pelvic girdle & n (\%) & $3(18)$ & $19(43)$ & $26(51)$ & $21(88)$ & 0.0023 \\
\hline External & n (\%) & $12(71)$ & $34(77)$ & $43(84)$ & $23(96)$ & 0.2566 \\
\hline $\mathrm{aPTT}^{\S}$ & $\mathrm{Sec}$ & $32(31-35)$ & $30(29-33)$ & $32(29-36)$ & $43(38-75)$ & $<0.0001$ \\
\hline $\mathrm{aPTT}>35^{\S}$ & n (\%) & $4(24)$ & $8(19)$ & $14(28)$ & $19(83)$ & $<0.0001$ \\
\hline INR $^{\|}$ & Ratio & $1(1.0-1.1)$ & $1.1(1.0-1.1)$ & $1.1(1.0-1.1)$ & $1.2(1.1-1.4)$ & $<0.0001$ \\
\hline INR $>1.2^{\|}$ & n (\%) & $0(0)$ & $3(7)$ & $2(4.1)$ & $9(39.1)$ & 0.0003 \\
\hline $\begin{array}{l}\text { Coagulopathic (INR > } 1.5 \text { and/or } \\
\text { aPTT >60) }\end{array}$ & n (\%) & $0(0)$ & $1(2.3)$ & $2(4.1)$ & $7(30.4)$ & 0.0037 \\
\hline Transfusion of PRBC & Units & $0(0-0)$ & $0(0-0)$ & $0(0-0)$ & $1.5(0-10)$ & 0.0004 \\
\hline Base excess** & $\mathrm{mmol} / \mathrm{L}$ & $-2(0--3.1)$ & $-1.9(-0.9--4.2)$ & $-3.4(-1.6--6.3)$ & $-6.2(-3.7--13.7)$ & 0.0306 \\
\hline CK maximum first $48 \mathrm{~h}$ & $U / L$ & $201(128-574)$ & $435(217-1356)$ & $1254(284-3606)$ & $1933(483-5398)$ & 0.2286 \\
\hline LDH maximum first $48 \mathrm{~h}$ & $U / L$ & $242(202-281)$ & $369(198-543)$ & $320(273-415)$ & $599(416-960)$ & 0.0009 \\
\hline
\end{tabular}

All data presented as median (with quartiles) or number of patients (\%)

*Analysed by Kruskal-Wallis test with Dunn's multiple comparison test or by $\chi^{2} /$ Fisher's exact test as appropriate with $p$ values presented in bold italics if $p<0.05$

+ Defined as AIS score $\geq 3$ in ISS region Head or neck

₹ Defined as major head trauma with no registered injuries to ISS regions Chest, Abdominal or pelvic contents, or Extremities or pelvic girdle

$\S 3$ patients excluded from analysis due to known anticoagulant treatment prior to injury and 3 patients excluded due to no aPTT test performed at admission

" 3 patients excluded from analysis due to known anticoagulant treatment prior to injury and 1 patient excluded due to no INR test performed at admission

**9 patients excluded from analysis due to no test performed at admission

NISS New Injury Severity Score; ISS Injury Severity Score; APTT activated partial thromboplastin time; INR International Normalized Ratio; PRBC packed red blood cells; $C K$ creatine kinase; $L D H$ lactate dehydrogenase 
median number of samples per patient was 6 (quartiles 5-10, range 1-35). Arterial samples were obtained in 969 instances (89\%), central venous samples in $17(2 \%)$, and peripheral venous samples in $105(10 \%)$. Sample type was undocumented for 3 samples (0.3\%). Peripheral venous samples were obtained from a control population consisting of healthy individuals ( 11 male, 9 female, median age 39 years, quartiles $32-49$, range $22-58$ ). There were no significant gender or age differences between patients and healthy controls, but the wide age range seen in the patient cohort was not reflected in the control population.

Serial samples taken from admission at regular intervals up to ten days were analyzed. IL-33 levels above the detection limit of our assay were only seen in a small subset of patients at admission $(\mathrm{n}=27$, median $33 \mathrm{pg} / \mathrm{mL}$, quartiles 12-76, range 3.3-172). Almost all of them were critically injured with a New Injury Severity Score (NISS) $>24$ (Fig. 1a, Table 1). IL-33 was below detection limit in all but one healthy control (Fig. 1a). This is in accordance with a previous study where only a small proportion of controls had detectable IL-33 (Rivière et al. 2016). In most patients with detectable IL-33 upon admission there was a subsequent rapid decay to below detection limit as soon as $8 \mathrm{~h}$ after injury (Fig. 1b). IL-33 levels were always highest in the first sample after admission, and as all initial samples from these patients were obtained 0:29-2:27 $\mathrm{h}$ after injury, this indicates release of a pre-stored alarmin rather than de novo synthesis. Supporting this assumption, the IL-33 decay rate from the first to the second sample was proportional to the initial concentration (data not shown), i.e. IL-33 obeyed first order kinetics. When including all IL-33 measurements within the first $10 \mathrm{~h}$ after injury the calculated half-life $\left(\mathrm{t}_{1 / 2}\right)$ was $1.4 \mathrm{~h}(95 \%$ CI 1.2-1.6; 64 samples from 28 patients). IL-33 was never detected beyond $12 \mathrm{~h}$ post injury, despite several patients suffering from post-trauma complications.

Our data appear to contradict $\mathrm{Xu}$ et al. (2017) who reported persistent IL-33 elevation for several days after severe trauma as well as detectable levels in healthy volunteers. The distributions of age, injury severity and injury mechanism are comparable in the two studies. We thus speculate that the observed differences in IL-33 levels may be due to different sensitivity/specificity in the detection assays, or to differences in pre-analytical conditions. To examine whether a large fraction of IL-33 was undetectable by our immunoassay, we performed supplementary experiments using immunoprecipitation and western blotting. We were not able to detect IL-33 in normal plasma or in patients with high IL-33 plasma concentration as determined by our ELISA, even when reducing the background noise by cleaning out a large fraction of albumin and immunoglobulin from samples (Additional file 1: Figure S1). It is worth noting that previous studies comparing various IL-33 immunoassays also showed low or undetectable levels of IL-33 in serum when using assays validated for use with human sera (Ketelaar et al. 2016; Rivière et al. 2016).

The rapid decay rate of IL-33 made it unfeasible to correlate absolute levels to clinical characteristics, in particular because the time after injury on admission varied with several hours between patients (Table 1). Instead, we assessed whether the group of critically injured trauma patients (NISS $>24, \mathrm{n}=75$ ) who had detectable IL-33 at admission (referred to as 'IL-33pos', $\mathrm{n}=24$ ) differed in terms of injuries and physiological findings from critically injured patients without detectable IL-33 ('IL33neg, $\mathrm{n}=51$ ) within the same injury severity group. There was a significant difference in time from injury to the first sample $(p=0.01)$, with more patients in the IL33neg group being admitted at later times after injury, suggesting missed detection due to rapid IL-33 concentration decay in some patients (Fig. 2a, Table 1). None of the 8 patients in the critical injury group who had suffered penetrating trauma had detectable IL-33 levels, however there was no significant difference regarding blunt vs. penetrating injury mechanism.

We looked closer at patient data for severity and anatomical localization of injuries. There was no significant difference $(p=0.34)$ when comparing NISS between the groups (Table 1, Fig. 2b). However, NISS differs from the original Injury Severity Score (ISS) in that the 3 most severe injuries are included regardless of body region. Thus, NISS correlates better with mortality than ISS (Lavoie et al. 2004), but does not differentiate between severe localized trauma and tissue damage across several body regions, the latter presumably causing more extensive release of IL-33. In accordance with this assumption, ISS was significantly higher in the IL-33pos group compared to the IL-33neg group (Fig. 2c), and the number of injured ISS body regions was substantially higher in IL33pos patients (median 5 vs. 3, Fig. 2d) with all IL-33pos patients having injuries to 3 or more ISS regions.

We also examined effects of different anatomical injury patterns (Table 1). There were no significant differences between the IL-33pos and IL-33neg groups regarding whether they were injured or not in the ISS regions 'Head or neck,' 'Face', or 'External', whereas a difference was seen in 'Abdominal or pelvic contents', 'Chest', and 'Extremities or pelvic girdle'. A similar pattern was observed when we compared maximum AIS injury severity between IL33pos and IL-33neg for each region. Using " 0 " as severity code for no injury, we found no significant difference in the regions 'Head or neck', 'Face', and 'External', whereas there were differences in 'Abdominal or pelvic contents' (median injury severity 3 for IL-33pos patients, 0 for IL33neg, $p<0.0001$ ), 'Chest' (median injury severity 4 and 2 , 


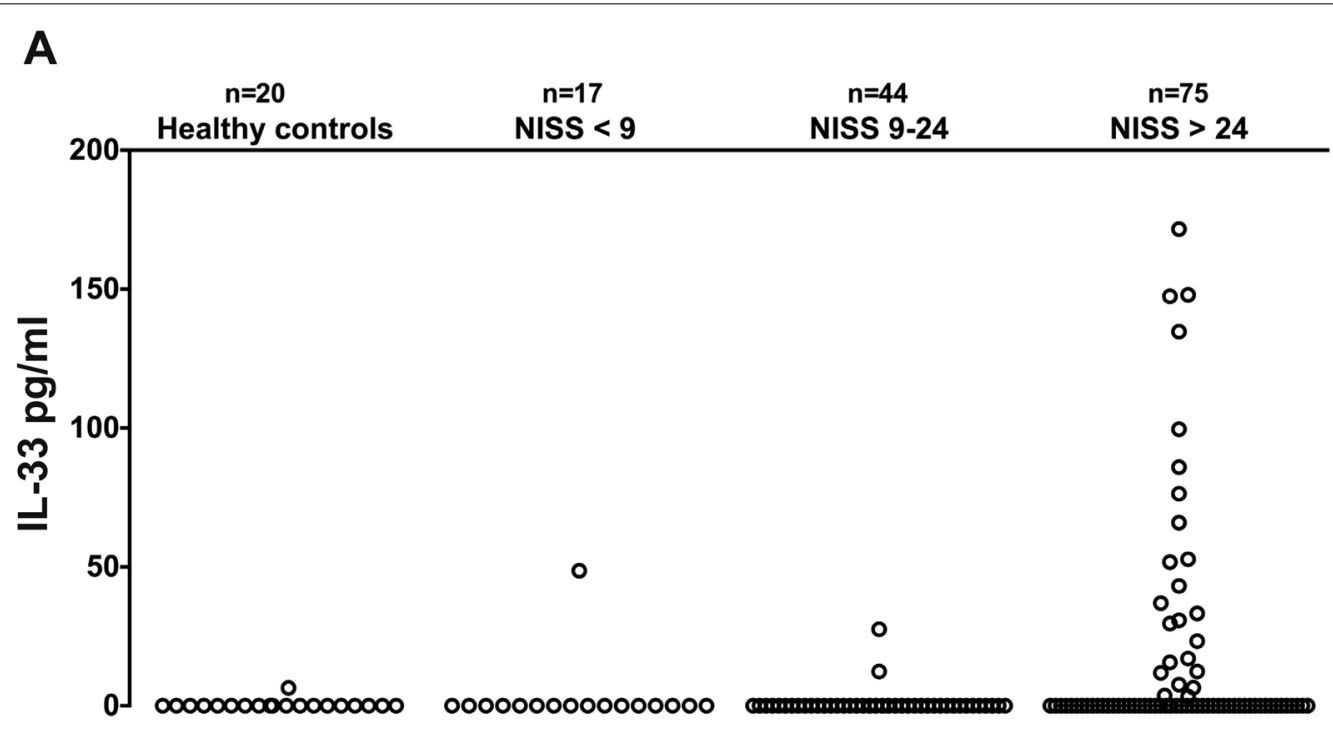

B

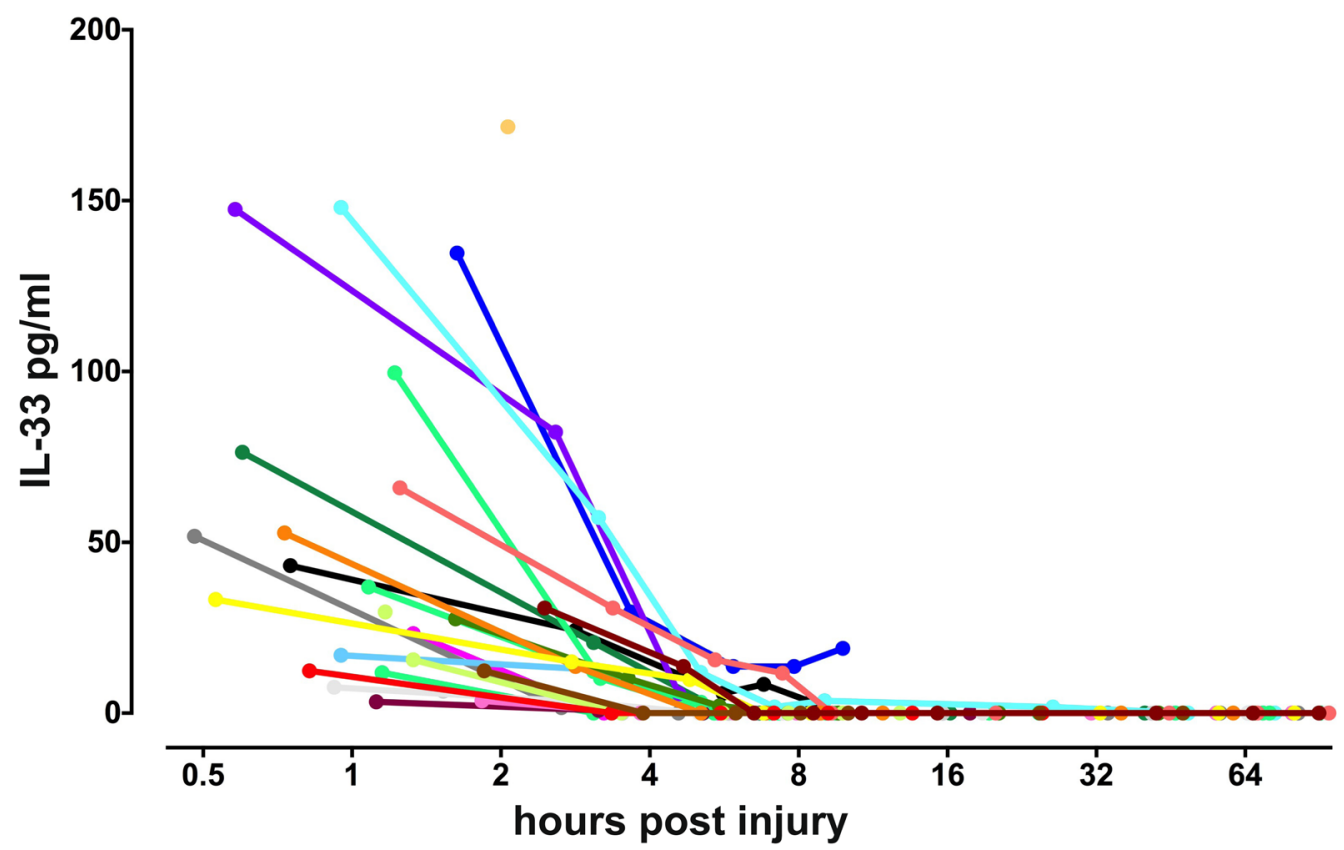

Fig. 1 IL-33 concentrations in healthy controls and in trauma patients stratified according to New Injury Severity Score (NISS). a IL-33 levels at admission. b IL-33 concentration kinetics in individual critically injured patients (NISS > 24) with detectable IL-33 at admission (one separately colored curve for each patient)

$p=0.04$ ), and 'Extremities or pelvic girdle' (median injury severity 3 and $1, p=0.007$ ). Finally, we explored the relative contribution of injuries in the ISS body regions in a multivariable logistic regression model for prediction of IL-33pos with maximal AIS severity code in each region as independent variables. "Informative Missing" was used to construct a coding system that allowed estimation of a predictive model despite the presence of missing values representing no injury in a particular body region. The minimum Bayesian Information Criterion was used to choose the best model through stepwise regression with backward selection. The only effect in this model 


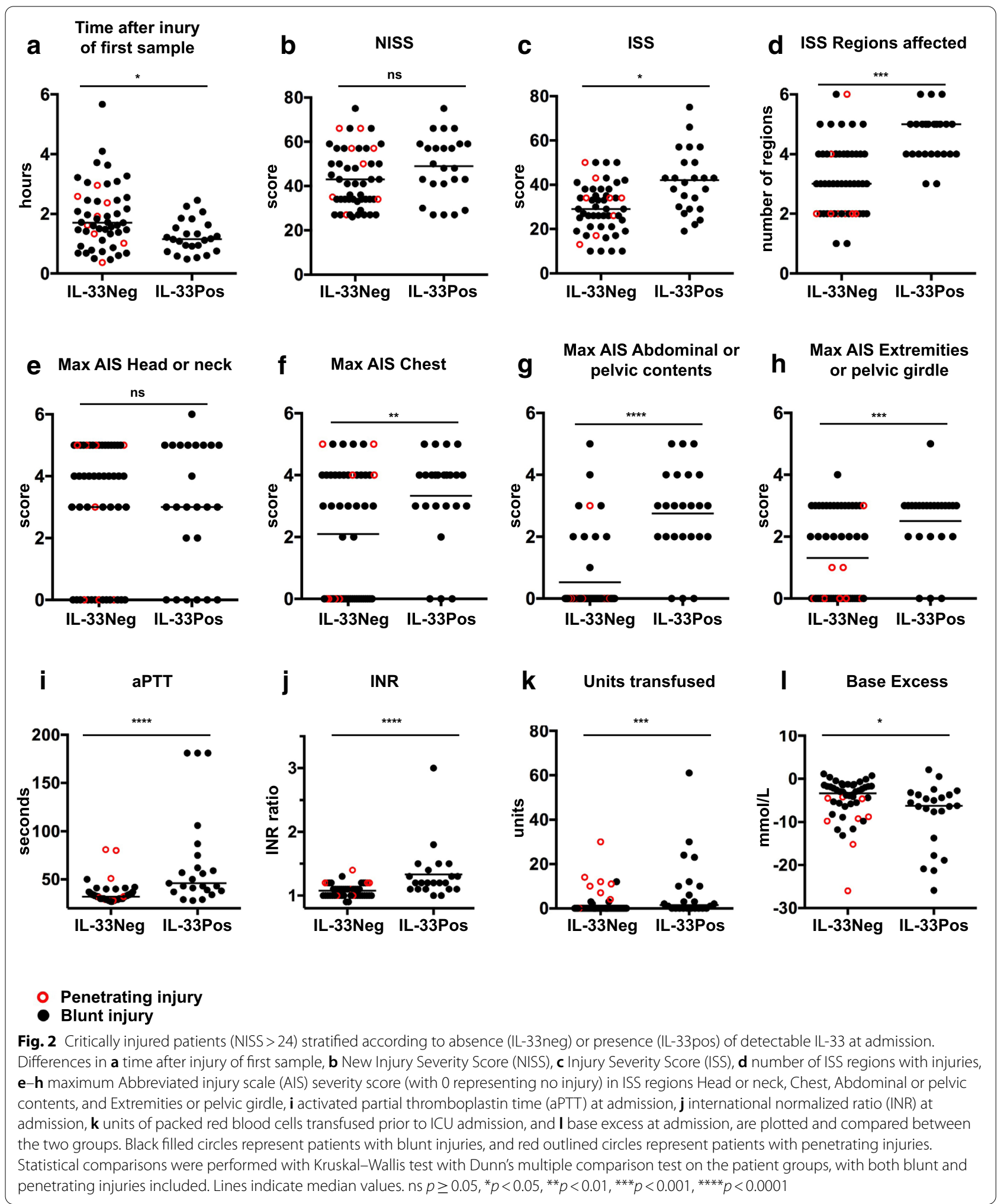


was whether or not there was an injury in the region 'Abdominal or pelvic contents' (OR 22.3 [95\% CI 5.7117]; $p<0.0001$; area under $\mathrm{ROC}$ curve $=0.82$ ).

Previous work by us and others has shown that nuclear IL-33 is constitutively expressed in endothelial cells along the vascular tree in humans (Küchler et al. 2008; Moussion et al. 2008). Taken together with the observed kinetics in this study which point to release of prestored IL-33, it is likely that stressed or damaged vascular endothelium is the main source of plasma IL-33 after trauma. Acute traumatic coagulopathy and associated transfusion requirements, although multifactorial in origin, are related to the severity of endothelial injury (Dobson et al. 2015). We therefore compared admission activated partial thromboplastin time (aPTT) and prothrombin time (PT, represented by international normalized ratio, INR) in IL-33pos and IL-33neg patients, after exclusion of 3 patients with known anticoagulant treatment regimens prior to injury. A large proportion of patients had abnormal coagulation, defined as INR $>1.2$ and/or aPTT $>35 \mathrm{~s}$ (Table 1). Importantly, both aPTT and INR were significantly higher in the IL-33pos group (Fig. 2i, j). Clinically significant coagulopathy, by some defined as INR $>1.5$ and/or aPTT $>60$ (Brohi et al. 2003), was only seen in 9 patients with critical injuries. Strikingly, 7 of these had detectable IL-33 at admission, including all 4 patients with an initial IL-33 level above $100 \mathrm{pg} / \mathrm{mL}$.

Although a relatively small proportion of patients received transfusions, the IL-33pos group received significantly more units of packed red blood cells than the IL33neg group (Fig. 2k, Table 1). Furthermore, most of the patients with high transfusion requirements in the IL33neg group had suffered penetrating injuries (Fig. 2k). In fact, all but one of the patients with penetrating injuries received transfusions, consistent with greater degree of disruption of large vessels. Accordingly, the difference in transfusion requirement between IL-33pos and IL33neg groups was even more pronounced when comparing only blunt injuries.

We consider it likely that the source of systemically released IL-33 is the vascular endothelium, which in humans shows strong constitutive expression of IL-33. Endothelial cells as primary source would be in agreement with the low IL-33 levels detected, as these cells represent a small tissue volume. A recent study showed that endotheliopathy can be detected as early as 5-10 min after trauma (Naumann et al. 2018), and this would fit with a process where trauma-induced endothelial damage causes an early release of alarmins. However, IL-33 is also expressed in various stromal and epithelial cells (Moussion et al. 2008; Pichery et al. 2012; Sanada et al. 2007), and contribution from other cell types is therefore also possible. In a study of patients undergoing liver resection, surgery resulted in a fivefold increase in post-operative serum IL-33 compared with pre-operative levels (Yazdani et al. 2017). Our finding that injuries in the ISS region 'Abdominal or pelvic contents' were particularly important for prediction of IL-33pos patients is well compatible with their results.

Although the number of deaths in our study was only 20 , there were significant associations between IL-33 and survival. 16 patients died during the first $48 \mathrm{~h}$ after trauma, five from massive haemorrhage and nine from major head injury defined as maximum AIS $\geq 3$ in ISS region Head or neck; a total of 16 died from or with major head injury. There were $46 \%$ non-survivors in the IL-33pos group and $16 \%$ in the IL-33neg group $(p=0.009)$, and admission IL-33 concentrations were significantly higher in non-survivors compared to survivors (median 7.6 vs. $0, p=0.007$ ) in those groups. IL-33 kinetics for survivors and non-survivors with and without major head injury is shown in Additional file 1: Figure S2.

Finally we compared early IL-33 kinetics to that of its decoy receptor sST2. As upregulation of sST2 after trauma has previously been described in several publications and the number of collected samples in the current study was large, we chose to analyze the full time course only in a few patients from each injury group and from a few healthy controls. The analyses confirmed that sST2 is abundantly expressed in normal plasma (range: $12-26 \mathrm{ng} / \mathrm{ml}$ ), yet in our trauma patients we observed striking increases starting from around $2 \mathrm{~h}$ after injury. The amplitudes of the responses were associated with injury severity (Fig. $3 \mathrm{a}-\mathrm{c}$ ). In the NISS $>24$ group peaks up to microgram levels were measured between 8 and $24 \mathrm{~h}$ after injury with subsequent decreases over the following days, with higher peak concentrations seen in patients who also had detectable IL-33 at admission (Fig. 3c). Importantly, the concentration was always lowest at the first time point, thus showing an inverse relationship to the profile of IL-33 (Fig. 3d). Moreover, the concentrations in admission samples were remarkably similar between different groups and also similar to healthy controls (Additional file 1: Figure S3). Together these observations point to an increase in protein produced de novo and secreted as a compensatory response to damage, consistent with previous data on SST2 as an inducible responder (Pascual-Figal and Januzzi 2015) upon e.g. NF-kB activation (Mildner et al. 2010).

\section{Conclusion}

We report high-resolution kinetic data addressing systemic release of IL-33 and document a rapid surge of IL-33 after severe tissue injuries. The findings strengthen the hypothesis that IL-33 is an early 


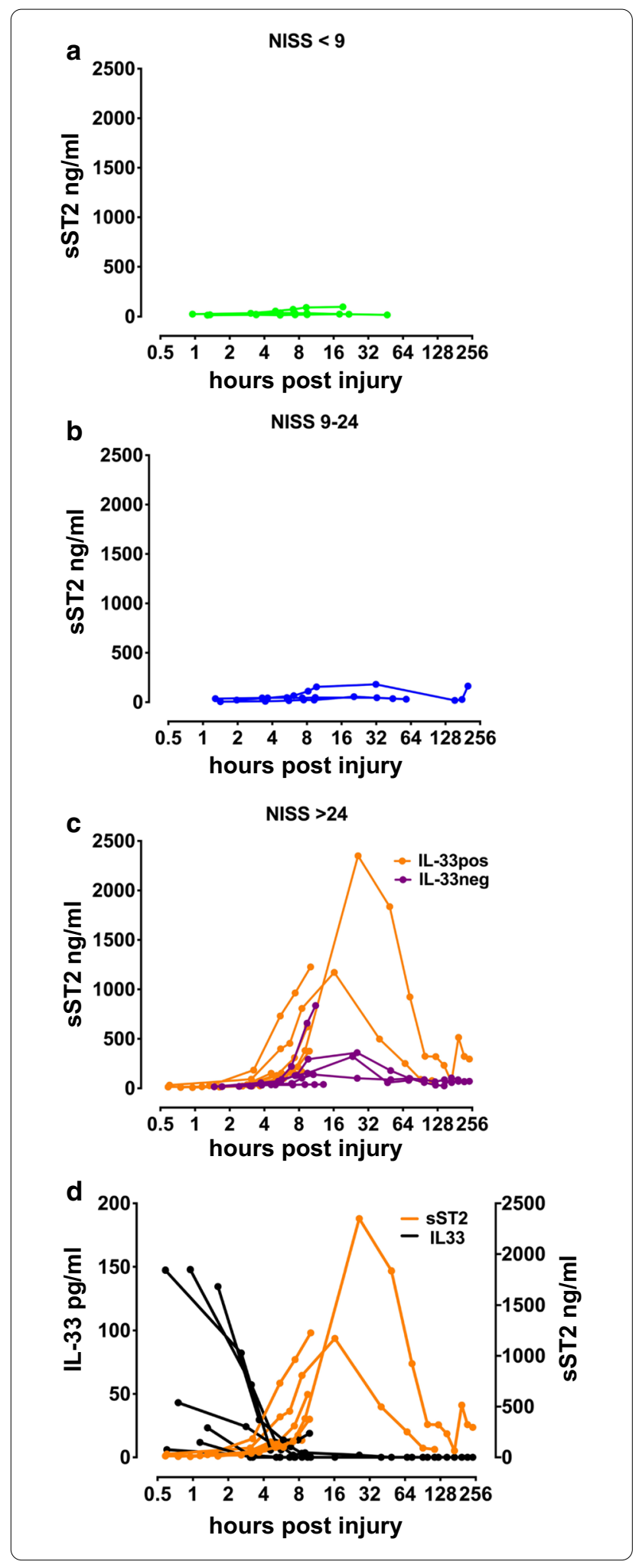

Fig. 3 sST2 measured by ELISA in plasma in a selection of trauma patients from the cohort. Concentration curves are plotted in separate panels $\mathbf{a}(n=3), \mathbf{b}(n=3)$, and $\mathbf{c}(n=12)$ according to New Injury Severity Score (NISS) groups. In c (critical injury, NISS > 24), $\mathrm{IL}-33 \operatorname{pos}(\mathrm{n}=7)$ and IL-33neg $(\mathrm{n}=5)$ patients are shown with orange and purple graphs, respectively. Panel $\mathbf{d}$ shows both IL-33 (black lines) and SST2 (orange lines) measurements in the IL-33pos NISS $>24$ group in the same graph

mediator of the immune response after tissue injury in humans. However, the highly pleiotropic nature of this cytokine with both pro-inflammatory effects on innate immune cells and anti-inflammatory effects on $\mathrm{T}$ regulatory cells makes it difficult to predict net effects of the IL-33 surge. Further work in relevant experimental models is therefore needed in order to decipher the exact function of this alarmin in human traumainduced immune responses.

\section{Abbreviations}

IL-33: Interleukin-33; HMGB1: High mobility group box 1 protein; NISS: New injury severity score; ISS: Injury severity score; AIS: Abbreviated injury scale; INR: International normalized ratio; PT: Prothrombin time; aPTT: Activated partial thromboplastin time; PRBC: Packed red blood cells; NF-kB: Nuclear factor kappa-light-chain-enhancer of activated B cells.

\section{Supplementary Information}

The online version contains supplementary material available at https://doi. org/10.1186/s10020-021-00288-1.

Additional file 1. Additional methods and figures.

\section{Acknowledgements}

We thank Ingrid Nygren Rognes, Ivan Jonassen Rimstad, Anne-Marie Siebke Trøseid, Jens Petter Berg, Linda Soilammi, Astrid Arnesen Hug, Erlend Skaga and Tomas Drægni for invaluable help with design, data collection and data analysis, Morten Hestnes and Hans Johansson for their continuing efforts at the Oslo University Hospital trauma registry, and Ulf Kongsgaard for facilitation of the study throughout.

\section{Authors' contributions}

TE conceived the clinical study and was responsible for overall design. OS designed and performed experiments, analyzed data and wrote the manuscript. WO and TE designed experiments, collected and analyzed data. CS, PL and LCP planned and performed experiments. TEM and GH designed experiments and analyzed data. All authors read and approved the manuscript.

\section{Funding}

The study was supported by grants from South-Eastern Norway Regional Health Authority.

\section{Availability of data and materials}

The data that support the findings of this study are available from Oslo University Hospital, but restrictions apply to their availability. They were used under license for the current study, and so are not publicly available. Data are however available from the authors upon reasonable request and with permission from Oslo University Hospital. 


\section{Declarations}

\section{Ethics approval and consent to participate}

The Regional committee for medical and health research ethics approved the protocol (2010/2014 REK Sør-Øst D). Patients were enrolled on admission, and written consent was obtained as soon as practically possible. A temporary written consent from the closest relative was obtained when patients were unable to consent. All material was destroyed if patients or relatives did not consent. The committee approved the use of biological material from patients who died before a fully informed consent could be obtained, and the use of written information with the possibility for withdrawal for patients who were transferred to other hospitals or discharged before consent could be obtained, provided that they were checked against the Norwegian national biomedical research reservation registry.

\section{Consent for publication}

Not applicable.

\section{Competing interests}

The authors declare that they have no competing interests.

\section{Author details}

1 K.G Jebsen Inflammation Research Centre, Institute of Clinical Medicine, Faculty of Medicine, University of Oslo, Oslo, Norway. ${ }^{2}$ Department of Pathology, Oslo University Hospital, Rikshospitalet, N-0027 Oslo, Norway. ${ }^{3}$ Department of Dermatology, Oslo University Hospital, Oslo, Norway. ${ }^{4}$ Department of Anaesthesiology, Division of Emergencies and Critical Care, Oslo University Hospital Ullevål, Oslo, Norway. ${ }^{5}$ Division of Critical Care, Institute of Clinical Medicine, Faculty of Medicine, University of Oslo, Oslo, Norway. ${ }^{6}$ Department of Immunology, Oslo University Hospital, Oslo, Norway. ${ }^{7}$ Reserach Laboratory, Nordland Hospital, Bodø, and K.G.Jebsen TREC, University of Tromsø, Troms $\varnothing$, Norway. ${ }^{8}$ Centre of Molecular Inflammation Research, Norwegian University of Science and Technology, Trondheim, Norway.

Received: 2 April 2020 Accepted: 8 March 2021

Published online: 26 March 2021

\section{References}

Bianchi ME. DAMPs, PAMPs and alarmins: all we need to know about danger. J Leukoc Biol. 2007;81(1):1-5. https://doi.org/10.1189/jlb.0306164.

Brohi K, Singh J, Heron M, Coats T. Acute traumatic coagulopathy. J Trauma. 2003;54(6):1127-30. https://doi.org/10.1097/01.TA.0000069184.82147.06.

Brunner M, Krenn C, Roth G, Moser B, Dworschak M, Jensen-Jarolim E, et al. Increased levels of soluble ST2 protein and lgG1 production in patients with sepsis and trauma. Intensive Care Med. 2004;30(7):1468-73. https:// doi.org/10.1007/s00134-004-2184-x.

Carriere V, Roussel L, Ortega N, Lacorre DA, Americh L, Aguilar L, et al. IL-33, the IL-1-like cytokine ligand for ST2 receptor, is a chromatin-associated nuclear factor in vivo. Proc Natl Acad Sci U S A. 2007;104(1):282-7. https:// doi.org/10.1073/pnas.0606854104

Dobson GP, Letson HL, Sharma R, Sheppard FR, Cap AP. Mechanisms of early trauma-induced coagulopathy. J Trauma Acute Care Surg. 2015;79(2):301-9. https://doi.org/10.1097/TA.0000000000000729.

Du Q, Weng J-F, Luo L-F, Cen M, Yu W-H, Zheng Y-K, et al. Serum ST2 as a potential prognostic biomarker for traumatic brain injury. Clin Chim Acta. 2018;487:145-52. https://doi.org/10.1016/j.cca.2018.09.035.

Granowitz EV, Santos AA, Poutsiaka DD, Cannon JG, Wilmore DW, Wolff SM et al. Production of interleukin-1-receptor antagonist during experimental endotoxaemia. Lancet. 1991;338(8780):1423-4. https://doi. org/10.1016/0140-6736(91)92725-h.

Halát G, Haider T, Dedeyan M, Heinz T, Hajdu S, Negrin LL. IL-33 and its increased serum levels as an alarmin for imminent pulmonary complications in polytraumatized patients. World J Emerg Surg . 2019;14(1):154-7. https://doi.org/10.1186/s13017-019-0256-z.

Haraldsen G, Balogh J, Pollheimer J, Sponheim J, Küchler AM. Interleukin-33 - cytokine of dual function or novel alarmin? Trends Immunol. 2009;30(5):227-33. https://doi.org/10.1016/j.it.2009.03.003.
Hirsiger S, Simmen H-P, Werner CML, Wanner GA, Rittirsch D. Danger signals activating the immune response after trauma. Mediators Inflamm. 2012 https://doi.org/10.1155/2012/315941.

Hwang PF, Porterfield N, Pannell D, Davis TA, Elster EA. Trauma is danger. J Transl Med. 2011:9(1):92-10. https://doi.org/10.1186/1479-5876-9-92.

Kakkar R, Hei H, Dobner S, Lee RT. Interleukin 33 as a mechanically responsive cytokine secreted by living cells. J Biol Chem. 2012;287(9):6941-8. https:// doi.org/10.1074/jbc.M111.298703.

Ketelaar ME, Nawijn MC, Shaw DE, Koppelman GH, Sayers I. The challenge of measuring IL-33 in serum using commercial ELISA: lessons from asthma. Clin Exp Allergy. 2016;46(6):884-7. https://doi.org/10.1111/cea.12718.

Kouzaki H, lijima K, Kobayashi T, O'Grady SM, Kita H. The danger signal, extracellular ATP, is a sensor for an airborne allergen and triggers IL-33 release and innate Th2-type responses. J Immunol. 2011;186(7):4375-87. https:// doi.org/10.4049/jimmunol.1003020

Küchler AM, Pollheimer J, Balogh J, Sponheim J, Manley L, Sorensen DR, et al. Nuclear interleukin-33 is generally expressed in resting endothelium but rapidly lost upon angiogenic or proinflammatory activation. Am J Pathol. 2008;173(4):1229-42. https://doi.org/10.2353/ajpath.2008.080014.

Lavoie A, Moore L, LeSage N, Liberman M, Sampalis JS. The new injury severity score: a more accurate predictor of in-hospital mortality than the injury severity score. J Trauma. 2004;56(6):1312-20. https://doi.org/10.1097/01. ta.0000075342.36072.ef.

Levy RM, Mollen KP, Prince JM, Kaczorowski DJ, Vallabhaneni R, Liu S, et al. Systemic inflammation and remote organ injury following trauma require HMGB1. Am J Physiol Regul Integr Comp Physiol. 2007;293(4):R1538-44. https://doi.org/10.1152/ajpregu.00272.2007.

Martin NT, Martin MU. Interleukin 33 is a guardian of barriers and a local alarmin. Nat Immunol. 2016;17(2):122-31. https://doi.org/10.1038/ ni.3370

Matzinger P. The danger model: a renewed sense of self. Science. 2002;296(5566):301-5. https://doi.org/10.1126/science.1071059.

Mildner M, Storka A, Lichtenauer M, Mlitz V, Ghannadan M, Hoetzenecker K, et al. Primary sources and immunological prerequisites for sST2 secretion in humans. Cardiovasc Res. 2010;87(4):769-77. https://doi.org/10.1093/ cvr/cvq104.

Molofsky AB, Savage AK, Locksley RM. Interleukin-33 in tissue homeostasis, injury, and inflammation. Immunity. 2015:42(6):1005-19. https://doi. org/10.1016/j.immuni.2015.06.006

Moussion C, Ortega N, Girard J-P. The IL-1-Like cytokine IL-33 Is constitutively expressed in the nucleus of endothelial cells and epithelial cells in vivo: a novel "Alarmin"? PLoS ONE. 2008. https://doi.org/10.1371/journ al.pone.0003331.

Müller S, Ronfani L, Bianchi ME. Regulated expression and subcellular localization of HMGB1, a chromatin protein with a cytokine function. J Intern Med. 2004;255(3):332-43. https://doi.org/10.1111/j.1365-2796.2003.01296

Naumann DN, Hazeldine J, Davies DJ, Bishop J, Midwinter MJ, Belli A, et al. Endotheliopathy of trauma is an on-scene phenomenon, and is associated with multiple organ dysfunction syndrome. Shock. 2018;49(4):420-8. https://doi.org/10.1097/SHK.0000000000000999.

Ottestad W, Rognes IN, Pischke SE, Mollnes TE, Andersson U, Eken T. Biphasic release of the alarmin high mobility group box 1 protein early after trauma predicts poor clinical outcome. Crit Care Med. 2019;47(8):e61422. https://doi.org/10.1097/CCM.0000000000003800.

Pascual-Figal DA, Januzzi JL. The biology of ST2: the international ST2 consensus panel. Am J Cardiol. 2015;115(7 Suppl):3B-7B. https://doi. org/10.1016/j.amjcard.2015.01.034.

Pichery M, Mirey E, Mercier P, Lefrancais E, Dujardin A, Ortega N, et al. Endogenous IL-33 is highly expressed in mouse epithelial barrier tissues, lymphoid organs, brain, embryos, and inflamed tissues: in situ analysis using a novel II-33-LacZ gene trap reporter strain. J Immunol. 2012;188:348895. https://doi.org/10.4049/jimmunol.1101977.

Rivière $E$, Ly B, Boudaoud S, Chavez H, Nocturne G, Chanson P, et al. Pitfalls for detecting interleukin-33 by ELISA in the serum of patients with primary Sjögren syndrome: comparison of different kits. Ann Rheum Dis. 2016;75(3):633-5. https://doi.org/10.1136/annrheumdis-2015-208557. 
Sanada S, Hakuno D, Higgins LJ, Schreiter ER, McKenzie ANJ, Lee RT. IL-33 and ST2 comprise a critical biomechanically induced and cardioprotective signaling system. J Clin Investig. 2007;117(6):1538-49. https://doi. org/10.1172/JCI30634.

Stoecklein VM, Osuka A, Lederer JA. Trauma equals danger-damage control by the immune system. J Leukoc Biol. 2012;92(3):539-51. https://doi. org/10.1189/jlb.0212072.

Sundnes O, Pietka W, Loos T, Sponheim J, Rankin AL, Pflanz S, et al. Epidermal expression and regulation of interleukin-33 during homeostasis and inflammation: strong species differences. J Invest Dermatol. 2015;135(7):1771-80. https://doi.org/10.1038/jid.2015.85.

Xu J, Guardado J, Hoffman R, Xu H, Namas R, Vodovotz Y, et al. IL33-mediated ILC2 activation and neutrophil IL5 production in the lung response after severe trauma: a reverse translation study from a human cohort to a mouse trauma model. PLoS Med. 2017;14(7):e1002365. https://doi. org/10.1371/journal.pmed.1002365.

Yazdani HO, Chen H-W, Tohme S, Tai S, van der Windt DJ, Loughran P, et al. IL-33 exacerbates liver sterile inflammation by amplifying neutrophil extracellular trap formation. J Hepatol. 2017;68(1):130-9. https://doi. org/10.1016/j.jhep.2017.09.010.

\section{Publisher's Note}

Springer Nature remains neutral with regard to jurisdictional claims in published maps and institutional affiliations.
Ready to submit your research? Choose BMC and benefit from:

- fast, convenient online submission

- thorough peer review by experienced researchers in your field

- rapid publication on acceptance

- support for research data, including large and complex data types

- gold Open Access which fosters wider collaboration and increased citations

- maximum visibility for your research: over $100 \mathrm{M}$ website views per year

At BMC, research is always in progress.

Learn more biomedcentral.com/submissions 